\title{
IMPORTÂNCIA DO ETANOL NA ATENUAÇÃO NATURAL DE ÁGUAS SUBTERRÂNEAS IMPACTADAS POR GASOLINA
}

\section{IMPORTANCE OF ETHANOL ON NATURAL ATTENUATION OF GROUNDWATER IMPACTED BY GASOHOL}

\begin{abstract}
CRISTINA CARDoso NuNES
Engenheira Química pela Universidade Estadual do Rio de Janeiro (UERJ). Doutora em Engenharia Ambiental pela Universidade Federal de Santa Catarina (UFSC)

HENRY XAVIER CORSEUIL

$\mathrm{PhD}$ em Engenharia Ambiental pela Universidade de Michigan. Professor Adjunto do Departamento de Engenharia Sanitária e Ambiental da Universidade Federal de Santa Catarina - Laboratório de Remediação de Águas

Subterrâneas (REMAS/UFSC)
\end{abstract}

Código ABES: 136/06 Recebido: 19/10/06 Aceito: 05/06/07

\section{RESUMO}

Nesse estudo, foram avaliados os resultados de um experimento de derramamento controlado de gasolina brasileira em água subterrânea durante 6,5 anos de monitoramento. A exaustão do etanol, aos 32 meses de monitoramento, e a significativa redução de mais de $90 \%$ da massa máxima dos compostos BTEX dissolvidos no meio, aos 79 meses, associadas ao uso dos receptores de elétrons e acúmulo de seus subprodutos metabólicos, demonstraram a eficácia da atenuação natural monitorada para contaminações de águas subterrâneas sem riscos imediatos a receptores críticos. Constatou-se ainda que a biodegradação do etanol permitiu a formação de uma biobarreira natural que, após a sua completa degradação, acelerou a taxa de biodegradação dos BTEX e impediu o avanço da pluma destes contaminantes.

PALAVRAS-CHAVE: Atenuação natural monitorada, biodegradação anaeróbia, gasolina, etanol, interpolação

\begin{abstract}
In this study, results of 6.5 years of a controlled release experiment with Brazilian gasoline in groundwater were evaluated. Ethanol exhaustion after 32 months and the significant dissolved BTEX mass reduction of more than $90 \%$ after 79 months, associated with the electron acceptors use and their metabolic byproducts accumulation, demonstrated the efficiency of monitored natural attenuation for groundwater contamination without immediate risk to receptors. Moreover, ethanol degradation provided a natural biobarrier formation that increased BTEX biodegradation rate and prevented the BTEX plume expansion.
\end{abstract}

KEYWORDS: Monitored natural attenuation, anaerobic biodegradation, gasohol, ethanol, groundwater, interpolation.

\section{INTRODUÇÃO}

A utilização de fontes de energia renovável é hoje meta ambiental de diversos países. A resolução energética americana de 2005 prevê o uso de 28 milhôes de $\mathrm{m}^{3}$ por ano de etanol ou biodiesel até 2012 (Schnoor, 2006). No Brasil, a gasolina comercial possui uma mistura de etanol entre 20 a $25 \%$ volume/volume, dependendo da disponibilidade de álcool no mercado, estando hoje vigente a portaria no. 51, de 22 de fevereiro de 2006, que fixa o percentual obrigatório de adição de álcool etílico anidro combustível à gasolina em vinte por cento (Brasil, 2006). O grande impulso na utilização do etanol como combustível no Brasil foi dado em 1975, com a criação do
Próalcool. Na época, o principal objetivo foi conter gastos com a importação do petróleo, onerada com o aumento do preço do barril devido à crise ocasionada pela OPEP(Organização dos Países Exportadores de Petróleo). Desta forma, graças a impasses econômicos no século passado, hoje o Brasil dispōe de uma tecnologia para a produção e uso do etanol em motores automotivos, contribuindo de forma pioneira para a qualidade ambiental do ar atmosférico. Contudo, além da preocupação mundial com a qualidade do ar, a preservação das águas subterrâneas tornou-se também uma questão estratégica para a política ambiental de todas as nações do mundo, dado seu importante papel como fonte de abastecimento e as diversas fontes poluidoras que degradam sua qualidade. A contaminação de águas subterrâneas por vazamentos de petróleo é uma das possíveis ameaças de sua qualidade devido à alta toxicidade dos hidrocarbonetos monoaromáticos (benzeno, tolueno, etilbenzeno e xilenos-BTEX). No Brasil, os padrōes de potabilidade estão previstos na portaria federal 518 (25.03.2004) do Ministério da Saúde, onde a concentração máxima permitida para o benzeno, tolueno, etilbenzeno e xilenos são de $5 \mu \mathrm{g} . \mathrm{L}^{-1}$, $170 \mu \mathrm{g} . \mathrm{L}^{-1}, 200 \mu \mathrm{g} . \mathrm{L}^{-1}$ e $300 \mu \mathrm{g} . \mathrm{L}^{-1}$, respectivamente.

Para a remediação de solos e águas subterrâneas impactadas com hidrocarbonetos de petróleo são utilizadas diversas tecnologias que podem ser classificadas em tecnologias ativas e passivas. Dentre as tecnologias ativas podem ser 
citadas a biorremediação acelerada in situ, aspersão de ar e bioventilação. A atenuação natural monitorada é considerada uma estratégia de remediação passiva, isto é, sem a intervenção do homem (Corseuil et al, 1996). Esta tecnologia está baseada na atenuação natural (redução de massa, concentração e mobilidade dos contaminantes na água subterrânea ao longo do tempo e distância do local de derramamento) devido a processos físico-químicos e biológicos naturais. Os processos que afetam a taxa de migração dos contaminantes são a advecção, a dispersão e a sorção. A biodegradação é o mais importante processo de transformação, causando a redução de massa dos contaminantes no meio impactado. Dentre as vantagens da atenuação natural monitorada podem ser citadas a redução dos custos totais em relação às tecnologias de remediação ativa $e$ a transformação dos contaminantes a compostos inócuos à saúde humana. O seu uso não é aconselhado em locais onde ela resultaria na migração dos contaminantes até locais críticos (poços de abastecimento de água, rios, etc). É importante destacar a relevância do custo da remediação de áreas impactadas para países em desenvolvimento, onde as demandas sociais e de infra-estrutura são muito altas e a questão ambiental é freqüentemente relegada a um segundo plano por ausência de alocação de recursos para este fim. Assim, a atenuação natural monitorada deve ser avaliada como uma estratégia adequada, dentro de seus limites de aplicação, para recuperação de áreas impactadas com hidrocarbonetos de petróleo. Além disso, a constituição da gasolina brasileira misturada com etanol acarreta conseqüências ambientais para a biodegradação como a preferência dos microorganismos pelo etanol em relação aos hidrocarbonetos de petróleo (Corseuil et al, 1998; 2004; Powers et al, 2001). Essas conseqüências representam um efeito negativo do etanol sobre a biodegradação dos compostos BTEX, isto é, a presença do etanol no meio impede a biodegradação dos compostos BTEX. Assim, tendo em vista as características particulares do combustível brasileiro, da mesma forma que o Brasil criou tecnologias de produção e uso do etanol nos motores automotivos, é fundamental que sejam desenvolvidas tecnologias nacionais de remediação adequadas à especificidade dos nossos combustíveis.
A biodegradação do etanol e dos hidrocarbonetos de petróleo pode ser considerada como uma reação de oxidação-redução realizada pela ação microbiana, onde os substratos (etanol e compostos BTEX) funcionam como doadores de elétrons (Chapelle, 2001). $\mathrm{Na}$ biodegradação aeróbia, o oxigênio dissolvido é o receptor de elétrons e, na degradação anaeróbia, os receptores de elétrons são o nitrato $\left(\mathrm{NO}^{3-}\right)$, o sulfato $\left(\mathrm{SO}_{4}^{-2}\right)$, o manganês (IV), o íon ferro (III) e o dióxido de carbono ( $\left.\mathrm{CO}_{2}\right)$. Assim o interesse desse trabalho é demonstrar a possibilidade de utilização da atenuação natural monitorada como estratégia para a remediação de áreas impactadas com gasolina brasileira. Essa demonstração é caracterizada a partir da redução de massa dos doadores de elétrons (compostos BTEX e etanol) como conseqüência do uso de receptores de elétrons (oxigênio dissolvido) e o acúmulo de seus subprodutos metabólicos (acetato, íon ferro (II) e metano) no meio, o que comprovaria que a atenuação dos contaminantes é causada por mecanismos biológicos de transformação.

A quantificação de contaminantes e de compostos químicos envolvidos na biodegradação em áreas impactadas é necessária para a avaliação dos riscos potenciais nos diversos usos da água subterrânea contaminada e do processo de biodegradação. Dentre os métodos utilizados para obtenção de estimativas dos contaminantes em áreas atingidas encontram-se: (1) soluções analíticas e numéricas de equaçôes para a determinação do fluxo da água subterrânea, do transporte dos contaminantes e coeficientes de biodegradação e (2) interpoladores para a obtenção de estimativas de massa e distribuição espacial. Como exemplos da primeira abordagem podem ser citados: o método de Buscheck e Alcantar, o método da correção pelo traçador e o método baseado no fluxo de massa dos contaminantes (Wiedemeier et al, 1999). Já no segundo grupo, encontrase o uso de métodos geoestatísticos e outros interpoladores determinísticos (Cooper e Istock, 1988; Kitanidis et al, 1996; Reed et al, 2004; Sturaro et al, 2000). Tanto a dependência do cálculo das variáveis hidrodinâmicas (por exemplo, velocidade do fluxo da água subterrânea) está sujeita a diversas incertezas, como os métodos baseados em concentrações são menos efetivos (como indicadores da atenuação natural) do que aqueles baseados no cálculo da massa total (Nyer et al, 1998). Por isso, esse trabalho buscou metodologias que evitassem as incertezas do cálculo das variáveis hidrodinâmicas e fossem baseadas no cálculo da massa total dos contaminantes na área monitorada. Assim, optou-se pela interpolação de dados para estimativa da massa dissolvida total dos doadores (compostos BTEX e etanol), receptores de elétrons (oxigênio dissolvido) e seus subprodutos metabólicos (acetato, íon ferro (II) e metano) na área monitorada. Além disso, a análise da biodegradação, através do uso dos receptores de elétrons e acúmulo de seus subprodutos metabólicos, apresenta-se como ferramenta técnica importante dada à oscilação das variáveis hidrodinâmicas, isto é, o efeito do transporte advectivo e dispersivo sobre os contaminantes, dificultando muitas vezes a determinação da diminuição de suas massas e a sua conseqüente atenuação. Deste modo, através de um monitoramento intensivo de longo prazo em um experimento de derramamento controlado de gasolina e etanol, este trabalho tem como objetivo investigar a real interferência do etanol e demonstrar a eficiência da atenuação natural monitorada como estratégia adequada para derramamentos de gasolina onde não há riscos para receptores.

\section{METODOLOGIA}

Esse estudo foi realizado a partir de um derramamento controlado de gasolina num aquífero localizado no campo experimental da Ressacada (Florianópolis - SC). Em dezembro de 1998, após o conhecimento detalhado da hidrogeologia da área (condutividade hidráulica, direção de fluxo, velocidade de migração da água subterrânea, etc.) e instalação de 45 poços de monitoramento multiníveis (profundidades variando entre 1 e 5 metros) foram liberados, ao nível do lençol freático (profundidade de 1 metro na data do derramamento), 100 litros de gasolina comercial brasileira, no local denominado fonte na Figura 1 , contendo $24 \%$ de etanol e $1 \mathrm{~kg}$ do traçador brometo de potássio. Durante mais de seis anos de monitoramento em quatorze campanhas de coleta foram analisados os seguintes parâmetros: benzeno, tolueno, etilbenzeno, xilenos totais, etanol, brometo, alcalinidade, 
$\mathrm{pH}$, potencial de oxidação e redução, oxigênio dissolvido, íon ferro (II), nitrato, sulfato, sulfeto, acetato e metano. A quantificação do metano foi realizada na fase líquida, sendo sua concentração de saturação em água $\left(\right.$ a $\left.25^{\circ} \mathrm{C}\right)$ igual a 22 mg.L L $^{-1}$ (Yalkowsky e He, 2003). Os compostos BTEX, etanol e metano foram analisados em um cromatógrafo gasoso (HP modelo 5890 - série II), equipado com detector de ionização em chama (FID). Os ânions brometo $\left(\mathrm{Br}^{-}\right)$, nitrato $\left(\mathrm{NO}_{3}^{-}\right)$, sulfato $\left(\mathrm{SO}_{4}^{-}\right)$, fosfato $\left(\mathrm{PO}_{4}^{-3}\right)$ e acetato $\left(\mathrm{CH}_{3} \mathrm{COO}^{-}\right)$foram analisados por cromatografia líquida (Dionex modelo DX -120), equipado com detector de condutividade iônica e coluna AS4A-SC. O método empregado foi o 4110B (AMERICAN PUBLIC HEALT ASSOCIATION, 1992). As análises do íon ferro (II) e sulfeto foram conduzidas em espectrofotômetro $\mathrm{HACH}$ - DR/4000, seguindo o método 3500-Fe D (método 1,10 fenantrolina) para o ferro (II) e o método 4500-S ${ }^{2-D}$ (método colorimétrico azul de metileno) para o sulfeto (American Public Healt Association, 1992). O método titulométrico foi utilizado na determinação da alcalinidade-Método 2320B (American Public Healt Association, 1992). O oxigênio dissolvido, potencial redox e o pH na água subterrânea foram medidos em campo, através de um analisador de água Micropurge ${ }^{\circledR}$ Flow Cell, modelo FC4000 (Fernandes, 2002). As análises das amostras da água subterrânea, coletadas nas profundidades de 1,$0 ; 2,0 ; 2,5 ; 3,5$ e 4,5 metros antes do derramamento, apresentaram os seguintes resultados: temperatura entre $17-24^{\circ} \mathrm{C}, \mathrm{pH}$ entre 5,0 $-5,3$, potencial de oxidação-redução entre +32 - +169 mV, oxigênio dissolvido entre $5-8 \mathrm{mg} . \mathrm{L}^{-1}$, nitrato entre 0,05 - $0,137 \mathrm{mg} \cdot \mathrm{L}^{-1}$, sulfato entre $0,3-4,3 \mathrm{mg} \cdot \mathrm{L}^{-1}$, sulfeto entre 0,006 a $0,014 \mathrm{mg} \mathrm{L}^{-1}$, ferro (II) entre $0-1,64 \mathrm{mg} \cdot \mathrm{L}^{-1}$, fosfato entre $0,05-0,54 \mathrm{mg} \cdot \mathrm{L}^{-1}$, metano igual a 0,01 mg. $\mathrm{L}^{-1} \mathrm{e}$ alcalinidade entre 4 - $30 \mathrm{mg} \cdot \mathrm{L}^{-1}$.

\section{RESULTADOS E DISCUSSÃO}

Para se quantificar a massa dos contaminantes, receptores de elétrons e seus subprodutos metabólicos foram comparados três métodos de interpolação (regressão polinomial, inverso da distância ponderada e mínima

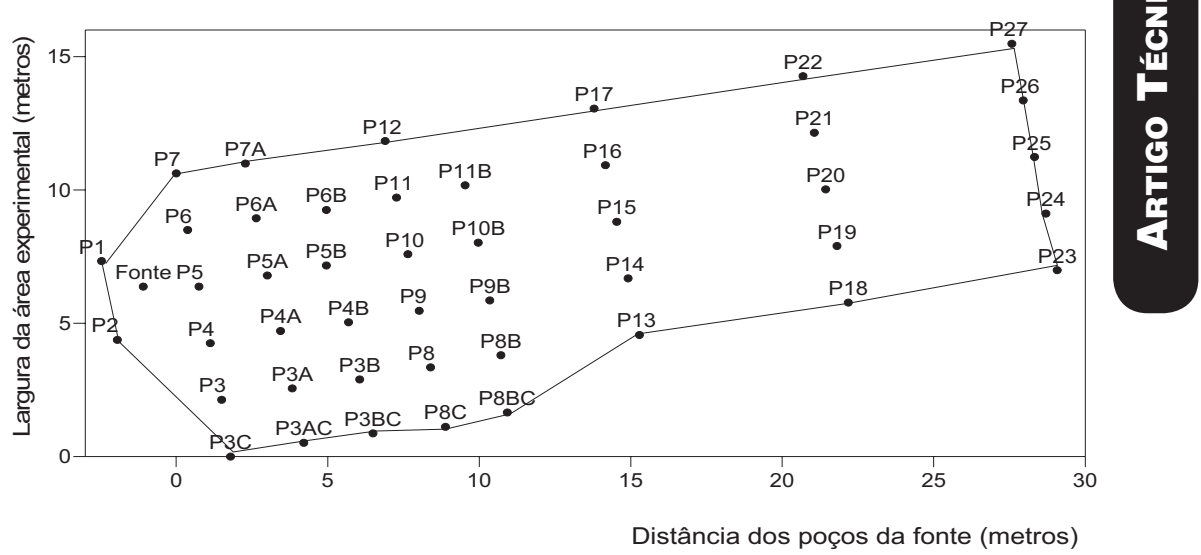

Figura I - Mapa da área experimental com os poços de monitoramento e limites da área interpolada

curvatura) (Loose et al, 1998; Reed et al, 2004). A escolha do melhor método foi baseada no erro médio quadrático (RMSE). Para o cálculo da interpolação foi definida uma área de interesse, a qual está representada na Figura 1, sendo que os poços extremos foram escolhidos como limites da área experimental. A fim de escolher o método com o menor erro, foi calculado o erro médio quadrático (RMSE) para os parâmetros analisados nos cinco níveis de profundidade monitorados $(\mathrm{n}=1$, $\mathrm{n}=2, \mathrm{n}=2,5 ; \mathrm{n}=3,5$ e $\mathrm{n}=4,5)$ ao longo de quatorze coletas. Quanto à estimativa de erro (RMSE), com exceção dos compostos BTEX, os demais parâmetros apresentaram erros baixos para os três métodos analisados (mínima curvatura, regressão polinomial e inverso da distância ponderada), destacando-se a mínima curvatura como método mais adequado (Nunes, 2006). A mínima curvatura representou um percentual superior a $90 \%$ de todas as coletas e níveis analisados com o menor erro percentual para as variáveis analisadas. Em relação à magnitude dos erros dos compostos BTEX, comparando-se os erros obtidos para essas variáveis com outros trabalhos que utilizaram interpoladores (Reed et al, 2004; Carvalho e Assad, 2002), verificou-se que mesmos os maiores erros obtidos se encontravam na sua grande maioria dentro dos limites obtidos para dados de campo. Deste modo, a mínima curvatura apresentou-se como o método com o menor erro de interpolação para a maioria dos parâmetros analisados.

Tendo sido escolhido, numa primeira etapa, o melhor método de interpolação para cada variável, os dados de campo foram tratados a fim de permitir uma análise bidimensional e a soma das massas obtidas para a área interpolada. Assim, as densidades volumétricas das concentraçôes ( $\mu$ g. $\mathrm{L}^{-1}$ ou mg. $\mathrm{L}^{-1}$ ) foram convertidas em densidades por área do aquiífero (mg. $\mathrm{m}^{-2}$ ou g. $\mathrm{m}^{-2}$ ) através da multiplicação pela espessura da pluma e porosidade do meio (Cooper e Istock, 1988). A porosidade efetiva do solo saturado foi quantificada em 20\% (Fernandes, 2002). Quanto à espessura das plumas, foram utilizadas as seguintes espessuras para os cinco níveis: 0,70 (nível um); 0,75 (nível dois); 0,75 (nível 2,5); um (nível três e meio) e um (nível quatro e meio) metro (Schneider et al, 2005). A massa foi calculada através da integração apresentada na equação (1), utilizando-se o programa Surfer 8.0. Foi considerada uma superfície definida por uma região retangular estendendose de $x_{\text {min }}$ a $x_{\text {max }}$ e $y_{\text {min }}$ e $y_{\text {max. }}$ :

Massa $=\int_{x_{\text {min }}}^{\mathrm{x}_{\text {max }}} \int_{y_{\text {min }}}^{y_{\text {max }}} f(x, y) d x d y$

onde x e y são as coordenadas geográficas e $\mathrm{f}(\mathrm{x}, \mathrm{y})$ é a função utilizada para a interpolação. O programa Surfer 8.0 realiza uma aproximação para obter as integrais unidimensionais através de algoritmos para integração numérica, dos quais foi escolhido o algoritmo de Simpson, conforme Loose et al, (1998).

No experimento da Ressacada foi utilizado o traçador brometo para o acompanhamento dos processos de migração, transporte advectivo e dispersivo, no meio monitorado. O composto escolhido é conservativo, não estando, portanto, submetido ao processo de biodegradação. Desta forma, para calcular o erro total do método (erro da interpolação, erro do algoritmo de Simpson e erros analíticos), realizou-se 
uma comparação entre a massa total de brometo adicionada no meio e a massa máxima obtida pela interpolação. A razão percentual da massa obtida do traçador pela massa total adicionada representou o erro global do método. Sabendo-se que foi utilizado $1 \mathrm{~kg}$ de brometo de potássio e que esse composto é conservativo e solúvel em água, a massa máxima possível de íon brometo dissolvida em água era de 670 gramas. Pela evolução do comportamento do traçador na área experimental (Figura 2), a partir da variação de massa, constatou-se que aos 32 meses o brometo atingiu o seu pico (631 gramas). Esse pico correspondeu aproximadamente a $94 \%$ da massa do íon brometo adicionado no meio, sendo, portanto, o erro total do método aproximadamente $6 \%$.

$\mathrm{O}$ mesmo procedimento referente à recuperação da massa realizado para o brometo foi efetuado para os compostos BTEX e etanol. A massa total de etanol e de compostos BTEX presentes na fonte, ou seja, na gasolina inicialmente liberada no aqüífero, era de $19 \mathrm{~kg}$ e de $7,03 \mathrm{~kg}$, respectivamente (Schneider et al, 2005). Utilizando-se a correção pelo traçador (94\%), a massa máxima do etanol obtida pelo método de interpolação foi de $12,8 \mathrm{~kg}$ (67\% da massa total presente na fonte) aos 16 meses. Assim, a diferença entre a massa total de etanol presente na gasolina $(19 \mathrm{~kg}) \mathrm{e}$ a massa máxima interpolada $(12,8 \mathrm{~kg})$ de etanol se deveu principalmente à biodegradação (Figura 2). Quanto aos compostos BTEX, a massa máxima interpolada foi $0,60 \mathrm{~kg}(8,6 \%$ da massa total disponível na fonte) e ocorreu aos 32 meses (Figura 2). Para os compostos BTEX, dada a hidrofobicidade desses compostos, não foi efetuada correção a partir do traçador. A grande diferença entre a massa total de BTEX presente inicialmente na gasolina e a máxima massa real de BTEX interpolada na água subterrânea pode ser atribuída ao lento processo de dissolução dos hidrocarbonetos monoaromáticos. A partir dos 32 meses, a massa do íon brometo começou a se reduzir na área experimental (Figura 2) porque a pluma de brometo já estava saindo da área de monitoramento (Nunes, 2006).

Em relação à atenuação natural dos substratos etanol e BTEX, constatou-se que a massa de etanol desapareceu totalmente 32 meses após o derramamento e que o processo de atenuação natural da massa dos hidrocarbonetos

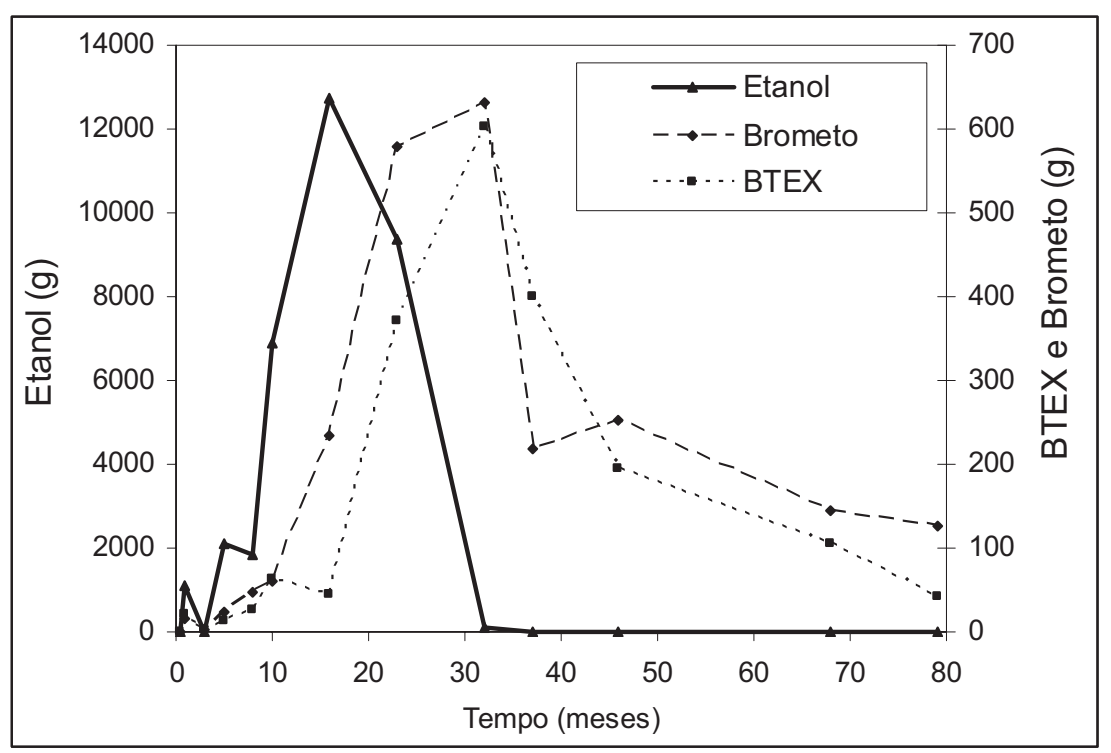

Figura 2 - Massas interpoladas de brometo, BTEX e etanol

monoaromáticos ainda continuava na última coleta realizada 6,6 anos após o derramamento. É importante destacar que não houve saída de massa de etanol e de compostos BTEX do meio monitorado durante o período do experimento, conforme avaliação das plumas de contaminação realizada por Nunes (2006) por meio da krigagem indicativa. Na Figura 2 pode-se verificar também a rápida diminuição da massa dos compostos BTEX dissolvidos na água subterrânea com o desaparecimento do etanol ocorrido 32 meses após o derramamento, o que indica a preferencial degradação do etanol em relação aos BTEX. Enquanto o etanol estava presente na água subterrânea, a massa dos compostos BTEX distribuída na água subterrânea aumentava porque o processo de transferência de massa da fonte para a água subterrânea dos hidrocarbonetos foi preponderante sobre o processo de transformação biológica. Considerando-se a massa dissolvida de BTEX aos 32 meses $(0,60 \mathrm{~kg})$ e a massa remanescente no meio aos 6,6 anos $(0,042 \mathrm{~kg})$, verifica-se uma redução superior a $90 \%$ da massa dissolvida dos contaminantes BTEX, o que demonstra a importância da atenuação natural para a remediação de águas subterrâneas impactadas com derramamentos de gasolina.

Para se avaliar a eficácia da atenuação natural é importante que se demonstre que a diminuição da massa dos contaminantes orgânicos ocorreu principalmente por transformações biológicas e não por mecanismos de transferência de fases (volatilização, por exemplo). Estas transformações biológicas podem ser demonstradas pela análise da variação de massa dos receptores de elétrons e seus subprodutos na área experimental. As variações de massa dos receptores de elétrons e seus subprodutos metabólicos estão representadas ao longo do tempo na Figura 3. Observa-se uma rápida diminuição da massa de oxigênio no meio, nos primeiros 5 meses, que foi ocasionada principalmente pela degradação do etanol. Assim, a disponibilidade de oxigênio dissolvido após 5 meses ocorreu principalmente por difusão nas bordas externas da pluma nas regióes de menor concentração de etanol e BTEX. Já para os processos anaeróbios, a ferro-redução e a metanogênese foram os principais mecanismos de degradação do etanol e dos compostos BTEX. As concentrações de metano superiores à saturação foram incluídas no cálculo da massa

Em um derramamento de gasolina com etanol, quando o produto entra em contato com a água subterrânea, o etanol tende a particionar rapidamente para a água subterrânea (Corseuil et al, 2004). Desta forma, ao contrário do que acontece em um derramamento de derivados de petróleo sem a presença de etanol, uma grande massa de substrato é transferida para a água subterrânea, ocasionando uma grande demanda bioquímica de oxigênio. Assim, a rápida exaustão do oxigênio dissolvido, 5 meses após o derramamento, tornou anaeróbia a região próxima à fonte, dificultando ainda mais a biodegradação 
dos compostos BTEX. Após 16 meses, a massa de etanol na água subterrânea era aproximadamente $67 \%$ da massa inicialmente presente na fonte. Entre 16 e 32 meses, o etanol foi biodegradado pelos mecanismos da ferro-redução e da metanogênese. A alta produção de íon ferro (II), acetato e metano até 32 meses corresponderam à biodegradação do etanol, já que a biodegradação dos compostos BTEX só foi predominante após a degradação do etanol (Figuras 2 e 3). A partir de 32 meses não foi possível observar o acúmulo desses produtos no meio devido à menor produção dos subprodutos metabólicos em presença de concentrações muitos menores dos compostos BTEX na água subterrânea.

A variação de massa dos contaminantes no meio monitorado é função da relação entre a taxa de transferência de massa da fonte para a água subterrânea e a taxa de biodegradação dos contaminantes. $\mathrm{O}$ aumento da massa dos contaminantes no meio monitorado está diretamente relacionado com a expansão da pluma dissolvida que tende a encolher somente quando a taxa de biodegradação for superior à taxa de transferência de massa dos contaminantes. A Figura 4 apresenta esquematicamente a relação temporal das massas interpoladas dos doadores, receptores de elétrons e seus subprodutos metabólicos, considerando-se que o etanol é o substrato preferencial dos microorganismos, e que a biodegradação dos compostos BTEX só foi significativa após o esgotamento do etanol. Como no experimento da Ressacada as condiçôes iniciais do aqüífero não revelaram a possibilidade significativa da utilização de nitrato e de sulfato como receptores de elétrons (Fernandes, 2002), eles não foram considerados na degradação anaeróbia nesse trabalho. Na Figura 4 a parte superior (a) apresenta a variação de massa dos substratos BTEX/etanol e a inferior (b), a massa dos receptores e seus subprodutos metabólicos ao longo do tempo. A variação de massa dissolvida de BTEX/etanol pode ser dividida em três fases. A primeira fase (A) correspondeu ao período onde a taxa de transferência de massa da fonte para a água subterrânea dos contaminantes foi maior do que a taxa de biodegradação. A segunda fase (B) representa, para o etanol, o período onde sua taxa de biodegradação foi maior do que a de transferência de massa da fonte para o

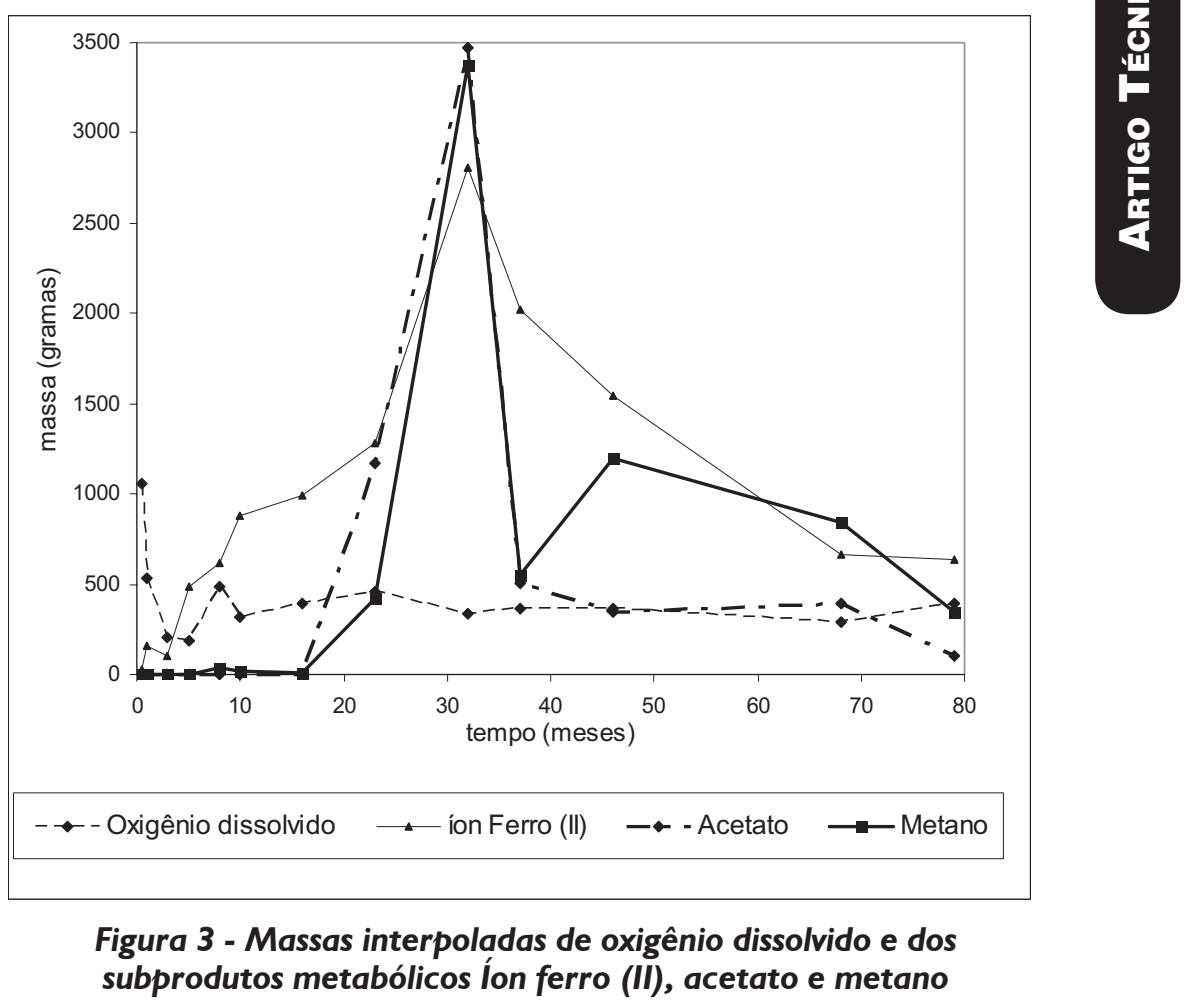

meio monitorado, e para os compostos BTEX, o período onde a taxa de transferência de massa dos aromáticos ainda foi superior à taxa de biodegradação. A última fase (C) apresentou o período onde o etanol havia se exaurido no meio e a biodegradação predominou na redução de massa dos compostos BTEX. A Figura 4b indica a existência de 4 fases geoquímicas distintas do processo de biodegradação dos substratos BTEX/etanol na água subterrânea. A fase (1) representou o período onde ocorreu a predominância da respiração aeróbia, sendo o seu início imediato e a sua duração de aproximadamente 5 meses. A fase (2), ocorrida entre 5 e 16 meses, foi caracterizada pela predominância da ferro-redução. A fase (3) ocorreu entre 16 e 32 meses e representou o período da concomitância da ferro-redução e da metanogênese. Na fase (4), entre $32 \mathrm{e}$ 79 meses, a metanogênese foi o processo predominante da biodegradação dos compostos BTEX. Neste período, a diminuição da massa de metano na área ocorreu devido ao esgotamento do etanol, à menor produção desse composto resultante da biodegradação dos compostos BTEX e também pela sua saída do meio monitorado (Nunes, 2006).

Ao contrário de tratamentos convencionais em reatores, onde a quantidade inicial de microorganismos e a disponibilidade de nutrientes são otimizadas, no ambiente subsuperficial natural, baixas populações microbianas estão presentes inicialmente e as condições nutricionais ótimas nem sempre são encontradas. Em derramamentos de misturas de gasolina com etanol, a disponibilidade de fontes de carbono na água subterrânea é completamente diferente dos casos onde não existe a adição do etanol aos combustíveis. No experimento da Ressacada as máximas massas de etanol e BTEX quantificadas na área foram, respectivamente, de $12,8 \mathrm{~kg}$ e $0,6 \mathrm{~kg}$. No entanto, uma significativa diminuição de massa do etanol na área experimental só foi observada a partir dos 16 meses, coincidindo com o início da fase metanogênica (Figura 4b). A redução da massa do etanol somente após o início da metanogênese ocorreu porque o tempo necessário para o início da biodegradação de compostos facilmente biodegradáveis como o etanol na água subterrânea, depende da presença de uma população inicial crítica de microorganismos (Corseuil e Weber, 1994). Desta forma, a imediata redução de massa dos compostos BTEX após o desaparecimento do etanol (redução em 93\% da massa dissolvida no meio) pode ser atribuída a grande massa de microorganismos desenvolvida com a biodegradação do etanol que intensificou a taxa de biodegradação anaeróbia 
dos hidrocarbonetos monoaromáticos na água subterrânea (Figura 2). A grande massa de microorganismos constituiu-se em uma zona bioreativa, isto é, uma região onde a comunidade microbiana é suficientemente ativa para metabolizar os substratos disponíveis. (Yocubal et al, 2003). Assim, podese dizer que inicialmente a presença do etanol interfere negativamente na biodegradação dos compostos BTEX, porém, após a sua completa degradação, o etanol tem um papel positivo no processo de atenuação natural dos BTEX acelerando a taxa de degradação destes compostos e impedindo o avanço das plumas de contaminantes.

\section{CONCLUSÕES}

Este estudo avaliou a eficácia da atenuação natural monitorada por meio de um derramamento controlado de gasolina com etanol em subsuperfície realizado no campo experimental da Ressacada (Florianópolis - SC). A concentração dos substratos (compostos BTEX e etanol), dos receptores de elétrons e de seus subprodutos metabólicos foi monitorada ao longo de seis anos e meio em 45 poços de monitoramento multiníveis e a quantificação da massa foi realizada através da interpolação dos dados de campo pelo método da mínima curvatura. Constatou-se que somente após a exaustão do etanol, ocorrida 32 meses após o derramamento, foi iniciada a redução de massa dos BTEX, o que demonstra o efeito negativo do etanol na degradação dos contaminantes aromáticos mais tóxicos. No entanto, após seis anos e meio de monitoramento, a massa remanescente de compostos BTEX dissolvida na água subterrânea correspondeu a apenas 7\% da massa máxima dissolvida durante todo o experimento. Esta massa continua ainda a diminuir estando localizada próxima a fonte derramada e sem riscos de migrar para pontos receptores críticos afastados.

Em relação ao uso dos receptores de elétrons e seus subprodutos metabólicos na biodegradação da mistura BTEX/etanol foram identificadas 4 fases distintas: predominância da respiração aeróbia (0-5 meses), predominância da ferro-redução (5-16 meses), concomitância da ferro-redução e metanogênese (16-32 meses) e predominância da metanogênese após 32 meses. Enquanto a biodegradação
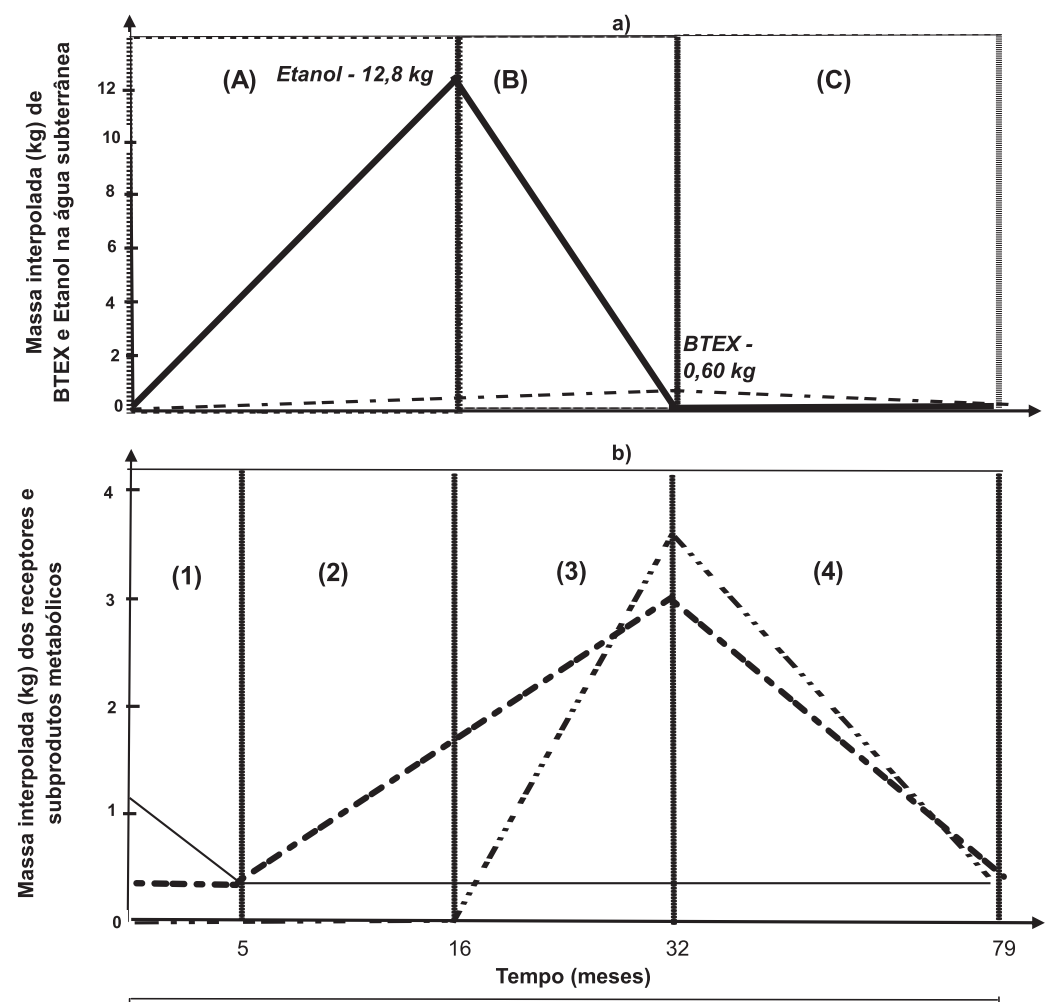

\begin{tabular}{|ll|}
\hline & Etanol \\
& Oxigênio dissolvido \\
& Metanogênese \\
(A) - Etanol e BTEX: Taxa de transferência de massa > Taxa de biodegradação \\
(B) - Etanol: Taxa de biodegradação > Taxa de transferência de massa \\
BTEX: Taxa de transferência de massa > Taxa de biodegradação \\
(C) - Etanol: Exaustão \\
BTEX: Taxa de biodegradação >Taxa de transferência de massa \\
(1) - Predominância da respiração aeróbica \\
(2) - Predominância da ferro-redução \\
(3) - Concomitância da ferro-redução e metanogênese \\
(4) - Predominância da metanogênese
\end{tabular}

Figura 4 - Modelo esquemático da variação dos receptores de elétrons e seus subprodutos metabólicos e biodegradação da mistura gasolina/etanol

do etanol envolveu as três primeiras fases, a biodegradação dos compostos BTEX ocorreu preponderantemente por processos metanogênicos. Desta forma, a exaustão do etanol, aos 32 meses, e a redução significativa de massa dos compostos BTEX, aos 79 meses de monitoramento, associadas à utilização do oxigênio dissolvido e ao acúmulo dos subprodutos metabólicos, demonstram a eficácia da atenuação natural monitorada como estratégia de remediação para casos de derramamentos de gasolina com etanol onde não haja riscos para receptores.

Deve-se ressaltar ainda a importância do etanol em águas subterrâneas impactadas por gasolina contendo etanol em sua mistura. Inicialmente, o etanol tem um efeito negativo pela sua preferencial degradação e pela grande demanda de receptores de elétrons o que impede a degradação dos contaminantes BTEX. No entanto, o efeito positivo da biodegradação do etanol é a formação de uma biobarreira reativa natural. Esta biobarreira, gerada pela degradação de uma massa de aproximadamente $13 \mathrm{~kg}$ de etanol, após a degradação do etanol, permitiu um aumento da taxa de degradação dos compostos BTEX dissolvidos na água subterrânea e impediu o avanço das plumas de contaminação. Assim, este estudo evidencia a necessidade de termos no país tecnologias adequadas à especificidade dos nossos combustíveis e dos cuidados que têm que ser tomados na importação de tecnologias de remediação que não considerem o papel do 
etanol em derramamentos de gasolina. Recomenda-se que uma maior atenção deve ser dada, tanto pelos órgãos de controle ambiental quanto pela empresas responsáveis pela avaliação das áreas impactadas, ao monitoramento do etanol na água subterrânea. Estudos, para os casos onde exista a necessidade de serem implantadas medidas ativas de remediação, estão sendo desenvolvidas na Fazenda Ressacada em parceria com a Petrobras.

\section{AGRADECIMENTOS:}

Este trabalho foi realizado com apoio financeiro da Petrobras, $\mathrm{CNPq}$ e CNPq/CT-Hidro. O estudo contou com a colaboração de diversos alunos de graduação, mestrado e doutorado em Engenharia Ambiental da UFSC bem como de profissionais do corpo técnico da Petrobras.

\section{REFERÊNCIAS}

AMERICAN PUBLIC HEALT ASSOCIATION (APHA). Standard Methods for The Examination of Water and Wastewater $18^{\text {th }}$ Edition. Washington, DC. 1992.

BRASIL. Ministério da Saúde. Portaria ministerial n. 518, de 25 de março de 2004. Lex: DOU 26/03/2004, seção I, p 266. Disponível em: $<$ http://www.cvs.saude.sp.gov.br>. Acesso em: julho 2004

BRASIL. Ministério da Agricultura, Pecuária e Abastecimento. Portaria ministerial no. 51, de 22 de fevereiro de 2006. Fixa em vinte por cento o percentual obrigatório de adição de álcool etílico anidro combustível à gasolina e revoga a portaria no 554, de 27 de maio de 2003 Lex: DOU de 23.02.2006. Disponível em: < http://www.agricultura.gov.br/. Acesso em: março 2006.

CARVAlHO, J. R. P., ASSAD E. D. Comparação de interpoladores espaciais univariado para precipitação pluvial anual no Estado de São Paulo. CENTRO NACIONAL DE PESQUISA TECNOLOGICA EM INFORMÁTICA PARA AGRICULTURA - CNPTIA. Campinas, (Comunicado Técnico da Embrapa Informática Agropecuária 33), 2002.
CHAPELLE, F.H. Ground - water Microbiology and geochemistry. 2 Ed. New York : John Wiley and Sons, 477p. 2001.

COOPER, R.M., ISTOCK, J.D. Geoestatistics applied to Groundwater contamination. II. Application. Journal of Envirommental Engineering 114 (2), 287-299, 1988.

CORSEUIL, H.X., WeBER, W.J. Potential Biomass Limitations on rates of degradation of monoaromatic hydrocarbons by indigenous microbes in subsurface soils. Water Research, v. 36, n. 6, p.1415-1423, 1994

CORSEUIL, H. X., PRADO, M. A., MARINS, M. D. Biorremediação Passiva de Aguas Subterrâneas Contaminadas por Derramamentos de Gasolina. In: $1^{\circ}$ CONGRESSO BRASILEIRO DE ENGENHARIA QUÍMICA, 1996, Rio de Janeiro. p.1442-1447. v.set/96 1996.

CORSEUIL, H.X., HUNT, C.S., SANTOS, R.C.F. The influence of the gasoline oxygenate ethanol on aerobic e anerobic BTEX biodegradation. Water Research, v. 32, n.7, p.2065-2072, 1998.

CORSEUIL, H. X., KAIPPER, B.I.A., FERNANDES, M. Cosolvency effect in subsurface systems contaminated with petroleum hydrocarbons and ethanol. Water Research, v. 38, n. 6, p.1449-1456, 2004

FERNANDES, M. Atenuação da Contaminação de Aqüifero submetido a derramamento de gasolina. 2002. 212f. Tese (Doutorado em Química).UFSC, Florianópolis, 2002.

KITANIDIS, P.K., SHEN, KUO-FUO. Geostatistical Interpolation of chemical concentration. Advances in Water Resources 19(6), 369-378, 1996.

LOOSE, B.; et al. Residence Time and Dispersion of Spring Snowmelt Runoff Esmerald Lake, California. Institute for Computacional Earth System Science, UC Santa Barbara, 1998. Disponível em: http:// www.icess.ucsb.edu/_brice/manuscript_wo_heat. pdf. Acesso em: abril de 2004.

NUNES, C.C. Dinâmica da Variação de Receptores de Elétrons e Subprodutos Metabólicos em Aguas Subterraneas impactadas por Derramamentos de Gasolina com Etanol. 2006. 244f. Tese (Doutorado em Engenharia Ambiental). UFSC, Florianópolis (SC), 2006. Disponível em: http://www.tede.ufsc.br/teses/ PGEA0260.pdf. Acesso em: outubro de 2006.

NYER, E.P., MAYFIELD, P., HUGHES, J. Beyond the AFCEE protocol for natural attenuation. Ground Water Monitoring \& Remediation 18(3), p. 70-77, 1998.
POWERS, S. E.; et al. The Transport and Fate of Ethanol and BTEX in Groundwater Contaminated by Gasohol. Critical Reviews in Environmental Science and Technology, v. 31, n. 1, p. 79-123, 2001.

REED, P. M., ELLSWORTH, T.R. MINSKER, B. S. Spatial Interpolation Methods for Nonstationary Plume Data. Groundwater 42(2), p. 190-202, 2004.

SCHNEIDER, M. R., SILVEIRA, O. D. CORSEUIL, H. X. Intemperismo da gasolina com etanol em sistemas subsuperficiais. In: $23^{\circ} \mathrm{CON}-$ GRESSO BRASILEIRO DE ENGENHARIA SANITÁRIA E AMBIENTAL, Campo Grande, Anais... Rio de Janeiro: ABES, 2005.

SCHNOOR, J.L. The debate is over. Environmental Science \& Technology 40(9), p. 2861, 2006.

STURARO, J. R., LANDIM, P. M. B.; RIEDEL, E. P. O emprego da técnica geoestatística da krigagem indicativa em Geotecnia Ambiental. Revista Solos e Rochas, vol. 23, no. 3, p. 157-164. 2000.

WIEDEMEIER, T.H.; et al. Natural Attenuation of Fuels and Chlorinated Solvents in the Subsurface. New York: John Wiley \& Sons, Inc. 617 p. 1999.

YALKOWSKY, S.H., HE, Y. Handbook of Aqueous Solubility Data: An Extensive Compilation of Aqueous Solubility Data for Organic Compounds Extracted from the AQUASOL dATAbASE. CRC Press LLC, Boca Raton, FL. 2003.

YOCUBAL, I.; et al. The influence of substrate and electron acceptor availability on bioactive zone dynamics in porous media. Journal of Contaminant Hydrology, v. 61, p. 219-237, 2003.

Endereço para correspondência:

Cristina Cardoso Nunes
Departamento de Engenharia
Sanitária e Ambiental
Centro Tecnológico - Laboratório
REMAS
Caixa Postal 476
$88040-970$ Florianópolis - SC -
Brasil
Tel.: (48) 333 I-7569
Email: crisnunes@ens.ufsc.br

Cristina Cardoso Nunes

Departamento de Engenharia

Sanitária e Ambiental

REMAS

Caixa Postal 476

Brasil

Email: crisnunes@ens.ufsc.br 